\section{China: where the new materialism interact}

Although scientists in China are being forced into a new role by rapid changes in Chinese life and closer contacts with the West, they are still guided by Marxist philosophy and the principle of social relevance. In the first of three articles on developments in Chinese science policy over the past year, Tong B. Tang, describes the organisation of research. In future articles, he will discuss higher education and the popularisation of science.
SCIENCE in China is growing increasingly quickly. It is based on ancient scientific heritage, the tradition developed under Marxism over the past 30-60 years, and the critical adoption of western methods and ideas. The importance of the last factor, however, has yet to be assessed. Although China stresses that its science will take a different path from that of western countries, its science and technology now seem poised to fill the economic and military roles which they have long occupied in industrialised countries.

China needs to promote the national economy and to deter what it calls international and regional hegemonists with greater help from the modernisation of science. Hence, the direction and prospect of its science are bound to be of profound interest, not only to scientists and science historians, but for the world.

Most scientific research is carried out at the 112 institutes of the Academia Sinica and at the 600 or more universities. The Academia, which celebrated its 30th anniversary in November 1979, is the designated "comprehensive centre of research into the natural sciences"'.

The entire pure and applied science budget is administered by the State Scientific and Technological Commission with Vice-Premier Fang Yi in charge. The Commission's preferences for different disciplines basically follow the National Plan for the Development of Science and Technology, a document of many volumes which was collectively agreed at the AllNation Science Conference in March 1978 (Nature, 6 April 1978, page 482). Briefly the orientation is towards agronomy and applied physics. The Plan was slightly modified when the three years of 1979-81 were recognised as an adjustment period for the national economy, and a conference was convened by the Commission in November 1979 to discuss the implementation of these modifications, particularly in the area of science and technology transfer.

The Commission allocates research responsibilities and funds to the Academia or the Education Ministry, and then successively to institutes or universities, sections or faculties, each represented by 'academic committees', and finally research groups. The Academia, nominally led also by Fang Yi, has Li Chang as its First Vice-President, and the Minister of
Vice Premier Fang Yi, in charge of China's science budget and head of the Academia Sinica, meets students in Beijing

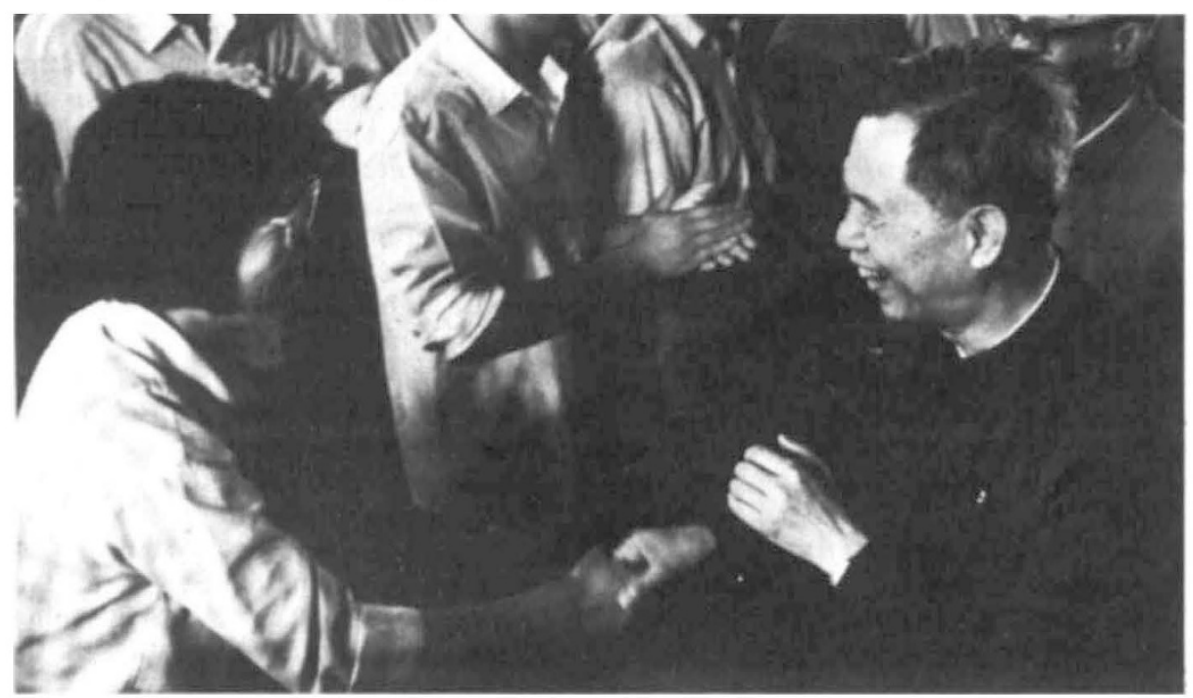

the historical

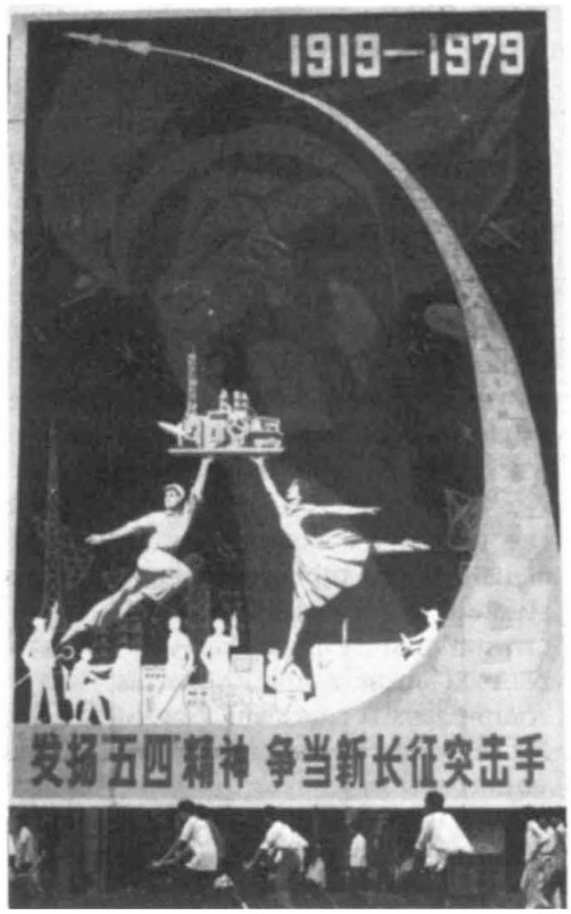

Giant propaganda poster stresses the political context of modernisation

Education is now Jiang Nanxiang. Key installations may be operated directly by the Academia or the Ministry or both. In addition, other ministries may support researchers whose work is of direct relevance to agriculture, forestry or industry. Some of them run their own chains of research institutes and training colleges. However, the infrastructure that couples the (long-term) activities of institutes and universities to research carried out at scientific farms and research and development at factories appears weak; one indicator is the relatively long delay that sometimes occurs between completion of a project and the application of its result in production.

Most research projects are assigned from above, but occasionally a research group submits a proposal to the academic committee of its section or department, whose complete programme will be reviewed by the institute or university. But it is unusual for a research group to branch out in its own research areas. This contrasts with western universities but probably resembles more the situation in government and most industrial laboratories. Last November, however, the Academia passed a resolution to give institutes the freedom of securing external funding by taking on contract work. The research unit will be able, after making sure that its state-assigned projects will be Tong $B$. Tang is a research fellow with the physics and chemistry of solids group at the Cavendish Laboratory, Cambridge 
completed on time, work on problems offered by a factory. Its time and expenses will be repaid by the factory either in one lump sum or as a percentage on the sale profit of the product concerned. It does not have to hand back to the state any net income that may result, but this procedure is said to be temporary only.

That the applied sciences continue to dominate in China is a reflection of the conviction that science receives its impetus from social needs: "from the very beginning the origin and development of the sciences have been determined by production". However the "socialist newborn-thing" of "inviting in" workers and peasants with practical experience to participate in experiments, and to a lesser extent that of scientists "going out" to work with the masses have largely gone. Now more 'pure' research is being encouraged. For example, two groups, one in Beijing, the other in Guangzhou, have started work on the detection of gravitational waves, and an observatory is planned near Kuming to carry out a comprehensive survey of the southern sky. More well known, perhaps, is the construction of a $50 \mathrm{GeV}$ proton synchrotron at Beijing (the 'BPS').

Opinion is divided on the social relevance of going in for high energy physics in a big way, especially among guest advisors such as the Nobel prize winners Chen-Ning Yang and Tsung-Dao Lee. But Li Chang explained at the AllNation Science Conference that particle physics, being a frontier subject, would play a leading role by stimulating advances in instrument technology and other fields. (The other two 'frontier sciences' which have been identified in a National Conference on Basic Sciences Planning held in October 1977 are astrophysics and cosmology, and the origin of life.) Fang Yi recently reiterated: "We consider basic research fundamental to all scientific progress".

Unfortunately, at present there is probably much duplication of applied research effort, on, for example, metal oxide semiconductor interfaces, stacking faults on oxidised silicon and other topics related to integrated circuit technology, rare earth metals as catalysts in petroleum refining, and lasers. All of these are among the priorities specified in the 1978-85 development plan. However, the nationwide coordination of research and resources and the exchange of results are hampered by bureaucratic barriers between ministries and administrative bodies, although the bureaucracy is no worse than in the West.

The Chinese are also discussing the relationship between central planning and local initiative. There is a trend for political authorities at the provincial or municipal level to take a greater part in the administration of science. Provided that democratic centralism is not eroded, and that the relationship of local autonomy to

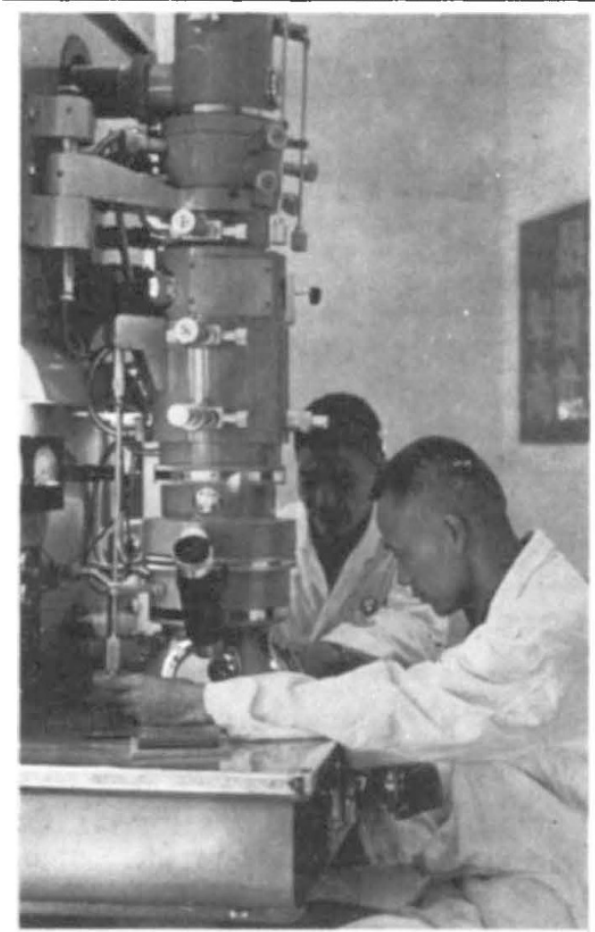

Worker-technicians Tsao Mu-Chuan and Chang Shih, working with China's first electron microscope

central control follows the changing situation, a limited devolution should make science more responsive to local needs without hindering the fulfilment of a unified state plan. Less tangible, though, are certain ideas on a 'mixed' system for research management, namely that science grows most quickly when it is also partly based on 'market economy' principles.

Many measures are still of a tentative nature. With some problems a variety of different solutions are currently being explored; a common solution will be nationally implemented only after an appraisal or reappraisal of all relevant experience. Up to the winter of 1978-79, policy statements were inclined to be contentiously forthright, for example, those concerning material incentives, learning from the West, and the professionalisation of education. Some of them were more "liberal" than in the years immediately before the Cultural Revolution, even than in the mid-1950s. Since spring of last year this tendency has been reversed. For instance, there has been more propaganda in the media and on public displays emphasising political work, revolutionary heroism, self-reliance and the danger of examination worship.

Western scientists in general and those of the social disciplines in particular are enthusiastic about the bourgeoning academic exchanges with China; about these more will be said in the next article. The Chinese welcome these developments but have firmly concluded that there is no question of importing wholesale modernisation or science and technology. The current slogan concerning foreign technology is, "use, learn, then modify, and finally invent". In April last year a meeting of academics in Beijing urged that Chinese science should retain its original character. At the First National Symposium on the Science of Science in August 1979, Li Chang reaffirmed that China will nurture a modern science, different from western science, by integrating the latter with the "dialectics of nature". Some Chinese have claimed that the dominant methodology endorsed by western science, while materialistic, is "metaphysical". This means that it contradicts the dialectical laws of thought, with its implicit assumptions of irreducible isolates and unitary identities.

Many events confirm that the prominent features of Chinese science in Mao's era have remained intact and are being further enriched. The Chinese understanding of science (and arts) as orientated towards man's struggle in economic production comes from Marxist historical materialism. Efforts to combine the modern and the traditional, initiated as part of Mao's policy of "walking on two legs", continue. For instance, the Peking College of Traditional Medicine is among the five key medical schools named by the Education Ministry, and traditional medicine is on the (essentially standardised) curricula of all fourth-year students training for western clinical practice or research. Philosophical arguments based on Marxism retain a respected guiding position in scientific controversies. For example in particle physics the quark model is overwhelmingly preferred to the bootstrap hypothesis of hadrons, and the high-sounding applications of catastrophe theory to human phenomena are generally ridiculed.

Further, guided by Mao's conceptions of "one divides into two" and the transformation of opposites, the Chinese want science to "change wastes into wealth and turn harmful into beneficial" in all agricultural and industrial processes. Lastly, to achieve modernisation and a healthy socialisation of science, the Party pledges to mobilise the whole people, in accordance with the dictum that "the mass movement is necessary in all work. Things won't go without the mass movement".

Nevertheless, in its quest for rapid modernisation, the Party has broadened the political base of decision-making and given more scope to the initiative of experts. Senior scientists now join forces with state officials to administer science and education. The press has devoted considerable space to polemics on democracy in academic discussions, or "academic freedom", meaning that the minority can sometimes be right and should always have the right to disagree. Indeed, the frustration of scientists may be understandable especially if it arises from the indifference or the dogmatism of bureaucrats. Still, the leadership will not want greater freedom to result in wasteful competition, an erosion of planned research or the ascent of deviationists and technocrats. 